\title{
50 Years of JEOL Electron Probe Micro Analyzer
}

\author{
H. Takahashi
}

JEOL Ltd., 1-2 Musashino, 3-chome, Akishima, Tokyo 196-8558, Japan.

Japan Electron Optics Laboratory (JEOL) was established in 1949. Since then, for the last over 60 years JEOL has developed and produced not only electron microscopes such as transmission electron microscopes and scanning electron microscopes but also various kinds of analytical instruments: electron probe microanalyzers, nuclear magnetic resonance spectrometers, mass spectrometers to be mentioned a few. Regarding electron probe microanalyzers (EPMAs), JEOL started their development in 1959 and announced the first commercial instrument: JXA-2 which is shown in Fig. 1, just 50 year's ago in 1961. Next year, JXA-3 was developed and sold to a few universities in Japan: Osaka University, the University of Tokyo, and Hokkaido University. It was also exported to several institutions in foreign countries, among which RCA is particularly mentioned here, because the company had Hillier's $1^{\text {st }}$ EPMA patent. These two machines laid the foundations of JEOL EPMA. The first attempt to install a data acquiring and processing system was made in JXA-5 in 1968.

An outstanding event in the history of electron microanalysis happened in 1970. EPMAs were used as a main instrument for analyzing the lunar rock brought back by Apollo 11. Many geologists around the world were engaged in analyzing the rock with EPMAs. The usefulness of EPMA was recognized in general public. Kushiro and Nakamura in Japan, who were actively participated in the project, published quantitative data [1]. For the quantitative analysis of silicates the correlation methods were successfully used in those days. For more reliable qualitative and quantitative data, it was realized that both hardware and software had to be improved by a few steps further. To meet the demand, JXA-733 was developed which machine is shown in Fig. 2. The column optics, software and fully computer-supported system among other things were improved in this machine. To improve the dispersion ability of very light elements the layered synthetic microstructure X-ray dispersion element has been developed. Unprecedented high probe currents with a small probe size were realized by the newly designed "mini-lens". The concept and the performance of the mini-lens was most favoravely described in the standard textbook of "Electron Microprobe Analysis" written by Reed [2]. The then one of the advanced mini-computer systems: DEC PDP-11 was installed in this machine. JXA-733 was extended with special order from Nippon Steel to JCMA-733 (Computer aided Micro Analyzer) to serve industrial needs [3]. The stage scanning method rather than the conventional beam scanning method was newly adopted, which method made possible the area analysis with an area as large as $90 \times 90 \mathrm{~mm}^{2}$. (In fact, the first computer controlled stage-scanning method was tried for JXA-5A [4].) Steel companies used this machine to measure the distribution of trace elements in steel ingots as shown in Fig. 2. At this development, JXA and JCMA-733 was fully semiconductorized without any vacuum tube. The computer system was modified and strengthened in JXA-8600. Multi-task analysis became possible in this machine and first network access was successfully tried to monitor the operation and data analysis from a meeting room located outside the machine room in 1989. To keep pace with rapid progress in computer systems, the computerization is also the fundamental norm even in EPMAs. A graphical user interface was introduced for easy operations in JXA-8800, Ethernet connection and many auto functions were also installed in this machine. 
In the $1980 \mathrm{~s}$, the $\mathrm{LaB}_{6}$ emitter was installed as option for the observation at higher magnification. It was realized that a smaller probe with increased brightness improved the quality of electron as well as X-ray -images, even if the penetration depth of the electron probe is determined by the accelerating voltage. This realization together with the special order from National Institute for Materials Science spurred to develop an FE-EPMA specially suited a Schottky type field emission gun [5]. This effort has led to the most current model: JXA-8530F shown in Fig.3.With this machine, imaging and analysis in a submicrometer range have become reality.

For the last 50 years, industrial as well as scientific needs for EPMAs have steadily increased. At present, randomly mentioned are some of the demands from users in industry: a backscattered electron image of rugged surfaces, standardless quantitative analysis, and fast, accurate and automated qualitative analysis. These needs and demands have been a driving force for the steady and sometimes dramatic improvements of the performance of EPMAs. Present day EPMAs can produce a large amount of high quality quantitative data without much difficulty in reasonable time. To deal with these massive data, color mapping becomes an indispensable tool to grasp the large scale as well as micrometer scale distribution of elements in the area of interest. Visualization with this mapping greatly helps clients and corporate managers as well as analysts to understand the analytical results. In some cases innovative technologies opened up a new field of applications. Recent success in the development of a soft X-ray spectrometer with high-energy resolution as well as high sensitivity might serve as this kind of innovation [6]. Still we are bound within the foresight of the great innovator: Dr. Raimond Castaing.

I express my heartily appreciation for many advices from senior engineers and Dr. M. Kikuchi. References

[1] I. Kushiro, Y. Nakamura., Proc. Apollo 11 Lunar Sci. Conf. (1970) 607.

[2] S. J. B. Reed, Electron Microprobe Analysis $2^{\text {nd }}(1993) 38$.

[3] I. Taguchi, H. Hamada., Analytical. Science (1985) 119.

[4] H. Ohyi, S. Okudera, K. Okumura, T. Soya, Electron Micros. Anaysis Group Conf. (1975) 175.

[5] H. Yamada, T. Okumura, T. Kimura, W. Knoll, Proc. of ICEM 15th DURBAN, (2002) 343.

[6] H. Takahashi et al., Microscopy \& Microanalysis, vol.16(supple.2), (2010)34.

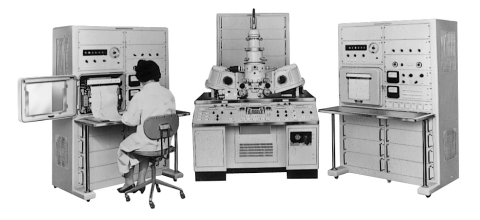

FIG. 1. First JEOL EPMA:

JXA-2 announced in 1961
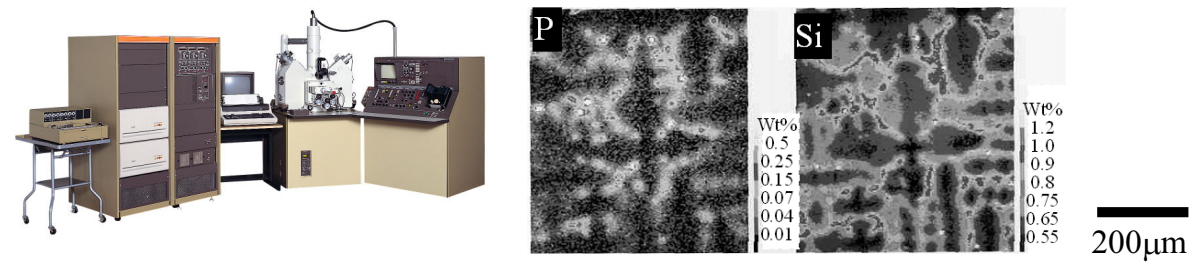

FIG. 2. JXA-733 and trace elemental mapping results (Dendrite structure of P, Si in a Steel).

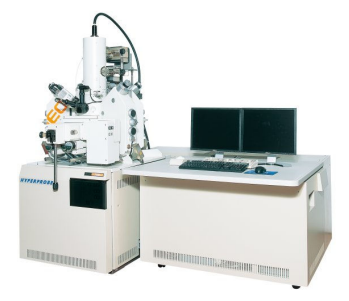

FIG. 3. Current FE-EPMA: JXA-8530F 